\title{
Safeguarding nutritional opportunities of first 1000 days of life during a pandemic: infant and young children feeding practices in the context of COVID-19 in India
}

\author{
Anila Varghese*, Monika Agarwal
}

\begin{abstract}
Department of Community Medicine and Public Health, King George's Medical University, Lucknow, Uttar Pradesh, India
\end{abstract}

Received: 15 May 2020

Accepted: 12 June 2020

\author{
*Correspondence: \\ Dr Anila Varghese, \\ E-mail: anivrghs@gmail.com
}

Copyright: (c) the author(s), publisher and licensee Medip Academy. This is an open-access article distributed under the terms of the Creative Commons Attribution Non-Commercial License, which permits unrestricted non-commercial use, distribution, and reproduction in any medium, provided the original work is properly cited.

\begin{abstract}
Children have milder clinical course and better prognosis from SARS-Co-V-2 infection. But the after-effects of this pandemic can have severe repercussions on nutrition of children, especially those who are already malnourished. Poor nutrition in the first 1,000 days of a child's life can lead to stunted growth, which is associated with impaired cognitive ability and reduced school and work performance. Misconceptions about breastfeeding, food insecurity hampering the procurement of nutritious food, competing household needs, psychological trauma that affects child care practices and disruption or reduced utilization of routine nutrition services can negatively impact infant feeding during the pandemic. If nutrition related factors contributed to about $45 \%$ of global under-5 mortality before the onset of COVID-19, the figures can increase if appropriate infant and young child feeding practices are not followed. Years of dedicated work has resulted in the infant feeding indicators we cite today. Efforts should be made to prevent backsliding, resulting in increased child malnutrition and mortality. Appropriate measures at the right time to protect, promote and support optimal IYCF practices and thereby safeguard the nutritional benefits of the first 1000 days of life during this pandemic, will pay rich dividends in terms of a healthier next generation.
\end{abstract}

Keywords: COVID-19, IYCF policies, Infant Nutrition, Malnutrition

\section{INTRODUCTION}

From the Wuhan city of China, SARS-CoV-2 spread across the globe in 2020, claiming more than 2.9 lakh lives in its wake till date. ${ }^{1}$ Although all age groups are susceptible to COVID-19 infection, most infected children appear to have a milder clinical course and better prognosis than adults. ${ }^{2,3}$ Yet, this pandemic may have detrimental effects on growth and development of children, especially those who were already in the throes of malnutrition and poverty. Just the year before the onset of COVID-19 pandemic, around 5.3 million children around the world did not make it up to their fifth birthday. ${ }^{4}$ Nutrition-related factors contributed to about $45 \%$ of these deaths. While children suffering from severe acute malnutrition are more than nine times more likely to die from infections than children who are not undernourished, a large number of deaths also occur among moderately and mildly undernourished children who may otherwise appear healthy. ${ }^{5}$

Thus, this pandemic can have severe repercussions on malnourished children. COVID-19 puts malnourished children at an ever-high risk of death and poor growth, development and learning in the children who survive. ${ }^{6}$ In 2019, 21.3 per cent children under age 5 years worldwide 
had stunted growth. ${ }^{7}$ In India, with an under-5 mortality of 36.6 per 1000 live births, $38 \%$ children under 5 years in the country are stunted and $20 \%$ are wasted. ${ }^{8}$ Poor nutrition in the first 1,000 days of a child's life (conception till second birthday) can lead to stunted growth, which is associated with impaired cognitive ability and reduced school and work performance. Realising the importance of nutrition in the first two years, several stakeholders at the international and country level have been actively involved in promoting age appropriate infant and young child feeding (IYCF) practices. Yet, only $41.6 \%$ infants in India are breastfed within one hour of birth, $54.9 \%$ exclusively breastfed for six months and $11.6 \%$ children aged 6-23 months are receiving an adequate diet. ${ }^{8,9}$

\section{PROBLEMS RELATED TO IYCF DURING COVID-19}

In addition to the already poor IYCF practices in normal circumstances, there are further challenges during emergencies to ensure that optimal infant and young child feeding is supported. ${ }^{10}$ Feeding practices are at risk of the aftershocks or indirect effects of the pandemic. These include misconceptions about breastfeeding, food insecurity hampering the procurement of nutritious food, competing household needs, psychological trauma that affects child care practices and disruption or reduced utilization of routine nutrition services. Those young ones whose first 1000 days of life overlap with the pandemic period are especially jeopardized.

\section{BREASTFEEDING DURING COVID-19}

Breast milk, the best source of immunity to the new born, has anti-viral properties due to virus-specific immune responses with immunoglobulin production, cellular immune responses and specific anti-viral cytokines. ${ }^{11}$ Breastfeeding also provides multiple physical and psychological benefits to mothers. In the context of an infectious disease outbreak, especially when the disease is poorly understood, policy makers must balance the benefits of breastfeeding against the risk of disease transmission through breastfeeding. ${ }^{12}$

During the 2014-2015 Ebola Virus Disease (EVD) outbreak, breastfeeding practices were negatively influenced as children were separated from infected mothers and front-line workers and caregivers faced challenges modifying breastfeeding practices. ${ }^{13}$

Fortunately, studies till date show that SARS CoV-2 does not get transmitted via breastmilk. ${ }^{14,15}$ The numerous benefits of skin-to-skin contact and breastfeeding substantially outweigh the potential risks of transmission and illness associated with COVID-19. ${ }^{16}$ The latest WHO guidelines state that infants born to mothers with suspected or confirmed COVID-19 are to be provided with access to health care services and should be supported in early initiation of breastfeeding, including early skin-to-skin contact, and to be exclusively breastfed, while applying the necessary hygiene precautions and ensuring measures are taken in order to avoid practices that separate babies and mothers or disrupt breastfeeding. In the event of separation from mother, expressed breast milk should be provided to the baby and in case of severe illness in mother wherein providing expressed breast milk is also difficult, the right substitutes should be given as per guidelines in the right manner. ${ }^{17}$ However, many newborns were separated from mothers who were confirmed/suspected cases of COVID-19, especially during the early phase of the epidemic when guidelines were lacking. Irrational use of Breast milk substitutes and feeding equipment (bottles, teats) also becomes a concern.

\section{ACTIONS FOR BREASTFEEDING MOTHERS ${ }^{17}$}

Mothers have to be counselled on the importance of respiratory hygiene especially during feeding. In case she has respiratory symptoms such as 'shortness of breath', a medical mask should be worn when near the infant. Hands have to be washed thoroughly with soap or sanitizer before and after contact with the child. All surfaces that are frequently touched should be routinely cleaned and disinfected. If the mother is severely ill with COVID-19 or suffers from other complications that prevent them from caring for the infants or continuing direct breastfeeding, expressed milk should be considered. If the mother is too unwell to breastfeed or express breast milk, she should explore the possibility of re-lactation (restarting breastfeeding after a gap), wet nursing (another woman breastfeeding or caring for your child), or using donor human milk based on cultural context, acceptability to mother, and service availability.

\section{COMPLEMENTARY FEEDING DURING COVID-19}

Breastfeeding must be complemented with safe and nutritionally adequate, solid, semi-solid and soft ageappropriate foods from six months of life. This complementary feeding period from 6 to 24 months is an important part of the first thousand days of life. ${ }^{18}$ It has been estimated that about 100,000 deaths in children younger than five years due to malnutrition could be prevented each year if complementary feeding was appropriate. ${ }^{19}$ But during the pandemic, mothers and caregivers face various challenges to providing appropriate feeds to their young ones.

\section{Food security}

The World Food Programme (WFP) has noted that the COVID-19 crisis is threatening to affect millions of people already made vulnerable by food insecurity and malnutrition. ${ }^{20}$ The expected economic depression and unemployment will contribute to increase in food insecure families. It has been found that the odds of a child being severely stunted, severely underweight or 
severely wasted are higher in severely food insecure households. $^{21}$ Following the lockdown in India from March 24, 2020, affordability of fresh and nutritious foods is a challenge in many places.

Public Distribution System continues to provide food grains with increased coverage and government has taken measures to ensure that the lockdown does not adversely affect the harvesting, transporting, procurement and storage of the food grains. Yet, due to unavoidable gaps in the system, cost of vegetables, fruits and poultry have increased tremendously in many areas. Mothers usually improve the quality of complementary feeds by addition of extra ghee, oil, sugar, jaggery and inclusion of fruits, vegetables, egg and poultry. These items are sometimes bought exclusively for infants in spite of low family income. In current crisis, it will be difficult for care givers to procure these items.

\section{Access to fresh, nutritious food and safe water}

Due to the restrictions related to the lockdown, it becomes difficult to ensure that fresh and nutritious food is provided to children. There is reduced availability and access to fresh seasonal fruits and vegetables, especially in the urban areas. Incidents of sale of old or rotten fish and poultry have also made parents cautious. Quite obviously, there has been increased usage of packed, ready to cook, highly processed food items that are rich in calories but nutrient deficient. Complementary feeds can thus lack the minimum meal diversity and hence adequacy. Access to safe drinking water compounds the problem.

\section{Food safety and myths}

At the beginning of the pandemic, there was concern about COVID- 19 transmission through food. Unlike bacteria, viruses cannot replicate in food, so viral contamination cannot cause deterioration of the food or food product or change organoleptic properties of the food. ${ }^{22}$ But it should be kept in mind that food items can act as fomites and hence it is important to stress on proper cleaning of fruits, vegetables, milk and food packets. This healthy habit can be retained even after the pandemic.

The FSSAI has notified food hygiene and safety guidelines for food businesses during the COVID 19 pandemic, including personal hygiene and the standard requirements of physical distancing and hand washing. ${ }^{23}$ Myths about food safety among child care givers have to be dealt with early as it can lead to exclusion of necessary food groups, thereby affecting diversity of the meal.

\section{Illness of the mother/caregivers}

Feeding a child is an art involving a process of play and emotional bonding between primary caregivers and the child. If the mothers or other caregivers become suspected or confirmed cases of COVID 19, it can affect complementary feeding adversely. If they are separated from the infants, coaxing the child to feed will be difficult. Children can be less receptive to a new caregiver and may refuse feeds. This will lead to decreased frequency and amount of meals and snacks. Thus, appropriate measures should be taken by the new caregiver to build trust of the child and continue feeding effectively. Hand hygiene for both caregivers and infants needs to be stressed. The practice of providing a separate plate/katori/spoon/glass to each child will also decrease disease transmission.

\section{Social factors}

Unfortunately, the pandemic led to certain communities being more severely hit than others. Households with COVID-19 cases may have to bear the stigma even after recovery. This can affect their access to quality food and increase psychological burdens, indirectly affecting IYCF practices. Also, there has been an increase in cases of domestic violence which puts mothers and children at risk. $^{24}$

\section{IDENTIFYING THE MOST VULNERABLE}

Young children are most vulnerable to any atrocity in the world. But during this pandemic, there are few groups of children who are at extra risk:

\section{Children who are part of the migrant exodus}

Due to lockdown and loss of jobs, many migrant workers started a long arduous journey home, some with their wives and young children. Ensuring provision of food for the infants during the journey is a difficult task. Even after these families reach their destinations, due to loss of jobs and lack of proper housing facilities, IYCF practices can be compromised.

\section{Homeless children and orphans}

If the condition of homeless children living on the streets and those in orphanages before the arrival of the pandemic was unacceptable, this new crisis will topple many of them into further malnutrition and death. The National Commission for Protection of Child Rights has asked the states to compile data of such disadvantaged children but given the present situation it may be a difficult task. ${ }^{25}$ Measures should be taken by the authorities to protect these vulnerable groups.

It is said that an estimated 42-66 million children could fall into extreme poverty as a result of the crisis this year, adding to the estimated 386 million children already in extreme poverty in $2019 .{ }^{26}$ In times of global crisis, starvation has potential to claim more lives than malnutrition. Extra care should be given to these vulnerable groups to prevent them from succumbing to the malnutrition and death. 


\section{DISRUPTION OF GOVERNMENT NUTRITION SERVICES}

IYCF practices were supported under Integrated Child Development Services Scheme (ICDS) via the Anganwadi centers (AWC) and active role of Anganwadi Workers $(\mathrm{AWW}) .^{27}$ Take home rations were being provided for lactating mothers and children. Anthropometry measurements of children were being taken at the AWC and specific care was given to those detected with malnutrition. A disruption in these services will affect the nutritional status. It has been reported that malnutrition screening services declined during the Ebola outbreak and that the prevalence of moderate and severe acute malnutrition increased among those screened postoutbreaks. $^{28}$

As per the National Food Security Act, 2013, provision of nutrition to the beneficiaries of Anganwadi services is a legal entitlement. ${ }^{29}$ Many states have taken action for delivery of the take home rations to the households. But only time can reveal the feasibility and effectiveness of this measure. Those states which had well- functioning public health care and Anganwadi services in the prepandemic era will definitely have an edge over others. This again highlights the importance of monitoring and periodic analysis of health services. This pandemic will indeed be a litmus test for our health and nutrition services.

\section{DIFFICULTY IN ACCESS TO COMMUNITY HEALTHCARE WORKERS}

Community health workers like auxiliary nurse midwife (ANM), accredited social health activist (ASHA) and AWWs are the backbone of IYCF activities at the community level. They are the main counsellors of families related to feeding practices. Village Health, Sanitation and Nutrition days, routine immunization sessions and house visits were opportunities for mothers to come in contact with these health workers. But due to the re-assignment of community health workers to address COVID-19 case detection and management, mobility restrictions and illness among the health workers themselves, the scope for skilled support has reduced.

\section{KEY FOCUS AREAS}

In order to sustain the advantages of appropriate feeding in first 1000 days of life and reduce malnutrition during a pandemic, concerted efforts are required. Faulty/inappropriate feeding will lead to a vicious cycle of malnutrition and increased susceptibility to infections. Strategies should be made for availability of clear guidelines, propagation of right messages on IYCF via mass media, identification of the vulnerable groups, ensuring household food security, and continued delivery of nutrition services of Anganwadi centres while maintaining social distancing norms. Standard infant feeding guidelines should be followed with appropriate respiratory and hand hygiene. IYCF indicators need to be closely monitored. Nutrition surveillance should be a priority even after the pandemic wanes off.

\section{CONCLUSION}

Years of dedicated work has resulted in the IYCF indicators we cite today. Efforts should be made to prevent backsliding, resulting in increased child malnutrition and mortality. Appropriate measures at the right time to protect, promote and support optimal IYCF practices and thereby safeguard the nutritional benefits of the first 1000 days of life during this pandemic, will pay rich dividends in terms of a healthier next generation.

Funding: No funding sources

Conflict of interest: None declared

Ethical approval: Not required

\section{REFERENCES}

1. WHO Coronavirus disease (COVID-19) situation Report 115 as on May 14, 2020. Available at https://www.who.i. Accessed on 15 May 2020.

2. Balasubramanian S, Rao NM, Goenka A, Roderick M, Ramanan A. Coronavirus Disease (COVID-19) in Children - What We Know So Far and What We Do Not? Indian Pediatr. 2020;57(5):435-42.

3. Dong Y, Mo X, Hu Y. Epidemiology of COVID-19 Among Children in China. Int Pediatr. 2020;145(6):20200702.

4. Global Health Observatory (GHO) data. WHO Under-five mortality. Available at https://www.who.in. Accessed on 3 May 2020.

5. Tracking progress on child and maternal nutrition. A survival and development priority. Available at www.unicef.org. Accessed on 3 May 2020.

6. Supporting children's nutrition during the COVID19 pandemic. Available at https://www.unicef.org. Accessed on 15 May 2020.

7. Malnutrition in Children - UNICEF DATA. Available at https://data.unicef.org. Accessed on May 3, 2020.

8. India (IND) - Demographics, Health \& Infant Mortality - UNICEF DATA. Available at https://data.unicef.org. Accesses on May 3, 2020.

9. National Family Health Survey-Fact sheet. Available at http://rchiips.org. Accesses on May 3, 2020.

10. Prudhon C, Maclaine A, Hall A, Benelli P, Harrigan $\mathrm{P}$, Frize J. Research priorities for improving infant and young child feeding in humanitarian emergencies. BMC Nutrition. 2016;2(1):27.

11. Prameela KK. Breastfeeding - anti-viral potential and relevance to the influenza virus pandemic. Med J Malaysia. 2011;66(2):166-9.

12. Brandt A, Oria ÓS, Kallon M, Bazzano AN. Infant feeding policy and programming during the 20142015 Ebola virus disease outbreak in Sierra Leone. Global Health Sci Practice. 2020;5(3):507-15. 
13. Kodish SR, Bio F, Oemcke R, Conteh J, Beauliere JM, Bailey PS, et al. A qualitative study to understand how Ebola virus disease affected nutrition in Sierra Leone a food value-chain framework for improving future response strategies. PLOS Neglected Trop Dis. 2019;13(9):43-9.

14. Chen H, Guo J, Wang C, Luo F, Yu X, Zhang W. Clinical characteristics and intrauterine vertical transmission potential of COVID-19 infection in nine pregnant women: a retrospective review of medical records. Lancet. 2020;395(10226):809-15.

15. Rasmussen SA, Smulian JC, Lednicky JA, Wen TS, Jamieson DJ. Coronavirus disease 2019 (COVID19) and pregnancy: what obstetricians need to know. Am J Obst Gynecol. 2020;4:415-26.

16. COVID-19: Resources for breastfeeding. WHO. 2020. Available at https://www.who.in. Accessed on 15 May 2020.

17. WHO EMRO Breastfeeding advice during the COVID-19 outbreak? Available at http://www.emro.who.in. Accessed on 3 May 2020.

18. Rathaur V, Pathweania M, Pannu C, Jain A, Dhar $\mathrm{M}$, Pathania $\mathrm{N}$, et al. Prevalent infant feeding practices among the mothers presenting at a tertiary care hospital in Garhwal Himalayan region, India. J Family Med Primary Care. 2018;7(1):45.

19. Bhutta ZA, Das JK, Rizvi A, Gaffey MF, Walker N, Horton $\mathrm{S}$, et al. Evidence-based interventions for improvement of maternal and child nutrition: What can be done and at what cost? Lancet. 2013;382:452-77.

20. The Covid-19 pandemic and Indian agriculture. Available at https://www.mssrf.org. Accessed on 3 May 2020.

21. Chandraseskhar S, Aguayo VM, Krishna V, Nair R. Household food insecurity and children's dietary diversity and nutrition in India. Evidence from the comprehensive nutrition survey in Maharashtra. Maternal Child Nutr. 2017;13:12447.
22. Kalaivani K, Ramachandran P. COVID19 in India: challenges to health, food security and nutrition. Bulletin Nutr Foundation India. 2020;41:2.

23. Food hygiene and safety guidelines for food businesses during Corona virus disease (COVID-19) pandemic. Available at https://fssai.gov.in. Accessed on 15 May 2020.

24. COVID-19 and violence against women. What the health sector/system can do. Available at https://www.womensaid.org.uk. Accessed on 8 May 2020.

25. COVID-19: NCPCR urges NGOs to stop feeding kids; asks them take children to shelters. The Week. Available at https://www.theweek.in/news/india. Accessed on 15 May 2020.

26. COVID-19 could cause hundreds of thousands of additional child death: UN - The Economic Times. Available at https://economictimes.indiatimes.com. Accessed on 15 May 2020.

27. Strengthening and restructuring of ICDS scheme. Ministry of Women and Child Development. Available at https://icds-wcd.nic.in. Accessed on 3 May 2020.

28. O'Fallon BJ, Barry MA, Brodish P, Hazerjian J. Rapid assessment of Ebola-related implications for reproductive, maternal, newborn and child health service delivery and utilization in Guinea. PLoS Currents. 2015;7:7.

29. National Food Security Act. The Gazette of India. Available at http:// www. egazette. nic.in. Accessed on 5 May 2020.

Cite this article as: Varghese A, Agarwal M. Safeguarding nutritional opportunities of first 1000 days of life during a pandemic: infant and young children feeding practices in the context of COVID19 in India. Int J Community Med Public Health 2020;7:2836-40. 